\title{
Editorial
}

\section{Tecnologia, Trabalho e Educação}

Ao longo dos últimos 20 anos, os países latino-americanos vêm sofrendo um conjunto de profundas transformações, associadas ao processo de reestruturação produtiva em nível internacional, que se caracteriza pela difusão de inovações tecnológicas e organizacionais nas mais diversas cadeias produtivas e pela reorganização dos mercados. No centro dessas transformações verifica-se um intenso processo de reorganização do trabalho e de elevação da produtividade, afetando o volume e a estrutura do emprego, o perfil e a hierarquização das qualificações e os padrões de gestão da força de trabalho. Entender a dinâmica e a natureza desse processo de mudança não é tarefa fácil, mas é fundamental para a formulação de estratégias de desenvolvimento econômico e social mais adequadas, ou seja, mais solidárias, equitativas e compatíveis com o meio ambiente. Nesse contexto, o debate sobre a relação entre tecnologia, trabaIho e educação assume uma enorme relevância.

Este número especial da revista do Educação e Sociedade reúne um conjunto de artigos, que são resultado do Programa de Pesquisa Ciência e Tecnologia, Qualificação e Produção, realizado e organizado pelo Cedes, e financiado pela Finep e pelo CNPq, entre 1995 e 1997. Este programa vem sendo executado por uma equipe interdisciplinar, distribuída entre várias universidades brasileiras com o objetivo de analisar este conjunto de transformações em nosso país. Entre os trabalhos que nos foram enviados, por razões de espaço, selecionamos oito, que constituem uma pequena amostra dos resultados atingidos por esse Programa. Os demais trabalhos, originalmente selecionados, serão publicados nos próximos números da revista.

O artigo que abre este número, de Eneida Oto Shiroma e Roselane Fátima Campos, faz um balanço do debate sobre reestruturação produtiva e qualificação nas pesquisas educacionais, a partir de uma revisão 
da bibliografia sobre o tema, produzida no Brasil durante a última década. As questões centrais analisadas são: polivalência ou educação politécnica, inovação tecnológica e demanda por qualificações, centralidade da educação básica e, por fim, competências e suas implicações para a empregabilidade.

Os seis artigos seguintes vão retomar esse debate, a partir de dados de pesquisas realizadas no âmbito de nosso Programa de Pesquisa. Vale destacar aqui que os estudos foram realizados não só em setores industriais (petroquímica, autopeças, linha branca e vestuário) e de serviços (bancos e comércio), como também em diferentes regiões do país (São Paulo, Rio Grande do Sul e Bahia).

Através de sua leitura, é possível compreender a variedade e a diversidade de situações concretas vivenciadas por homens e mulheres participantes destes processos de transformação. Eles nos permitem distinguir diversos ritmos de difusão de inovações, as diferenças entre o "discurso" e as práticas, num processo de ensaio e erro, e permanente tensão entre conservação e inovação. Nesse sentido, rompem com o determinismo tecnológico e a camisa-de-força da polarização do debate entre efeitos "positivos" ou "negativos" das novas tecnologias. Além disso, enriquecem a discussão sobre o significado social da dimensão "qualificação".

Nadya Castro, em seu estudo sobre a indústria petroquímica, vai nos mostrar como, em contextos nos quais se instabilizam as condições da ação gerencial (mercados de produtos, modos de regulação estatal das condições de competição e relações sindicais), a construção de formas de consentimento tem na negociação em torno da qualificação uma importante "moeda-de-troca". Para isso, a autora analisa o nexo entre pressões competitivas, natureza das relações industriais e reestruturação das políticas de pessoal em duas conjunturas, mostrando o impacto das ações gerenciais sobre as regras de recrutamento e de mobilidade, a organização do trabalho e os símbolos de status prevalecentes entre os grupos de trabalhadores na empresa. Desta análise depreende-se a centralidade da qualificação na constituição de um campo de negociação das novas condições de trabalho no cotidiano fabril. Ainda na fábrica, os trabalhos de Maria Rosa Lombardi (autopeças) e Raquel Gazzana (vestuário) descrevem com cuidado as mudanças no conteúdo das tarefas e nas condições de trabalho de operárias e operários e suas percepções sobre essas mudanças, chamando a atenção para a diferença de gênero na percepção da multifuncionalidade. 
Os trabalhos de Sônia Larangeira (bancos) e o de Marilis Lemos de Almeida (comércio), combinando dados agregados e estudos de caso, permitem-nos avançar na análise das tendências relativas ao volume e às condições de emprego e também no conteúdo das qualificações. É interessante observar que o processo de reestruturação das empresas nesses setores está baseado nas mesmas "receitas" utilizadas na indústria: redução de níveis hierárquicos, programas de qualidade, informatização.

Apesar da diversidade dos estudos e do enfoque dos autores, é interessante observar que o conjunto de trabalhos aponta para algumas tendências comuns: a) redução do emprego, associado à elevação da produtividade; b) intensificação do trabalho; e c) mudanças no conteúdo do trabalho e redefinição das atribuições dos trabalhadores.

Nesse contexto de mudanças observa-se a revalorização de atitudes, habilidades e atributos obtidos via escolarização formal (básica, técnica e mesmo universitária), cujo significado está amplamente discutido nos artigos que compõem este número da revista. O que queremos destacar aqui é que este processo está induzindo a redefinição ou a reconfiguração das relações entre empresas e diferentes instituições, especialmente as do sistema educacional, processo que tem como variável importante a proximidade geográfica e social entre essas instituições.

$\mathrm{O}$ artigo de Gitahy et. all. discute essa reconfiguração a partir de pesquisa realizada em um segmento da cadeia produtiva de linha branca localizada no interior de São Paulo, próxima à cidade de Campinas, enquanto o trabalho de Brisolla et al. vai discutir a natureza das relações entre universidades, empresas e governo, a partir de um estudo realizado na Unicamp, no mesmo período. Assim, nos aproximamos da discussão da construção social das redes produtivas e suas novas formas de articulação institucional, tema recorrente na literatura dos anos 90 .

Finalmente, cabe destacar que o processo de reestruturação produtiva que atinge os mais diversos setores e regiões de nosso país, alterando a divisão do trabalho não só no interior de empresas, como entre empresas e as relações entre elas e as instituições do sistema educacional, está ocorrendo num contexto marcado pela atomização da ação coletiva, em que o mercado de trabalho é extremamente desfavorável aos trabalhadores e os sindicatos de trabalhadores se encontram bastante fragilizados. 
